\title{
Young, Alone, and Young Alone During a COVID-19 Lockdown
}

\author{
Tiffany Field ${ }^{1,2 *}$, Shantay Mines ${ }^{2}$, Samantha Poling ${ }^{2}$, Miguel Diego', Debra Bendell ${ }^{2}$, Connie Veazey ${ }^{2}$ \\ University of Miami/Miller School of Medicine, USA \\ ${ }^{2}$ Fielding Graduate University, USA
}

Article Info

\section{Article Notes}

Received: September 12, 2020

Accepted: October 30, 2020

\section{*Correspondence:}

Dr. Tiffany Field, Ph.D., University of Miami/Miller School of Medicine, USA; Fielding Graduate University, USA; Email: tfield@med.miami.edu.

( 2020 Field T. This article is distributed under the terms of the Creative Commons Attribution 4.0 International License.

\section{Keywords:}

COVID-19 Lockdown

Young living alone

Loneliness

Depression

Fatigue

\section{Abstract}

The effects of age (young versus old) and living status (alone versus with others) during the COVID-19 lockdown were assessed via a Survey Monkey questionnaire on 260 individuals (18-82 years). Both age and living status and their interaction effects were explored via ANOVAs on scales for health, media use, mood states including anxiety and depression, posttraumatic stress symptoms, fatigue and sleep disturbances. ANOVAs were conducted via a median split on age as well as on a group comparison of young (20-40 years) versus old (60-80 years) individuals. The results of these two types of data analyses were consistent on most variables, suggesting that the young versus the old experienced more stress, anxiety, depression, and PTSD symptoms as well as greater fatigue and sleep disturbances. And, they reported fewer health activities. Significant effects were also noted for the alone versus living with others' groups including less engagement in exercise and work at home by the alone individuals as well as more stress, depression, fatigue, and PTSD symptoms. A significant age by living condition interaction effect suggested that the young living alone had the highest depression scores. The experiences that were common to the young, the living alone, and the young living alone were being lonely, depressed and fatigued. These results highlight the importance of prevention/intervention for the young, the alone and the young alone during lockdowns like COVID-19.

\section{Introduction}

Several negative symptoms have been reported by researchers in several different countries experiencing COVID-19 lockdowns including symptoms of posttraumatic stress, depression, anxiety, and sleep disturbances. For example, in China, posttraumatic stress was the primary symptom during the COVID-19 lockdown ${ }^{1}$. This is not surprising given that PTSD has been prevalent in previous epidemics including SARS ${ }^{2}$. Posttraumatic stress was apparently sufficiently prominent in the Italian COVID-19 lockdown (29.5\%) that a group of investigators designed a specific COVID-19 posttraumatic stress scale ${ }^{3}$. High levels of depression and anxiety have also been reported for the Italian lockdown ${ }^{4}$. Sleep problems, which frequently relate to these negative mood states, have been noted in at least two Italian lockdown samples ${ }^{5,6}$. And, sleep disturbances were reported for the same time period during the Australian lockdown ${ }^{7}$. These data collectively highlight the importance of identifying a profile of individuals most at risk for these problems. Both being young and living alone are two demographic characteristics that are emerging as a potential profile for prevention/intervention protocols during pandemics.

Both beingyoung and living alone have been significantly correlated with all of the above problems in a recent Survey Monkey study on the COVID-19 lockdown ${ }^{8}$. In that study, stress and sleep disturbances were correlated with young age and living alone. Others have noted associations between being young and reporting more anxiety and 
depression. For example, in a Chinese lockdown sample, anxiety was noted in $35 \%$ of the sample, depression in $20 \%$ and sleep in $18 \%{ }^{9}$. The younger participants (less than 35 years) experienced more anxiety and depression symptoms, although they surprisingly did not report more sleep disturbances. The authors labeled the combined anxiety and depression "hypochondriac concern about getting the virus". In the Australian sample already mentioned, psychological distress occurred more frequently in the younger age group (18-45 years $)^{7}$. And, these researchers reported that greater psychological distress also occurred in those who were not in a relationship. Although these findings are based on crosssectional samples that cannot address causality, the collective data suggest that being young and alone may be a risk profile for psychological problems and sleep disturbances during lockdowns like the COVID-19 pandemic.

The data analyses in the present study were designed to focus on age (young/old) and living condition (living alone/living with others) as demographic risk factors for psychological distress and sleep disturbances during the COVID-19 lockdown. The data, based on a Survey Monkey sample, were analyzed via ANOVAs on a median split by age as well as by comparisons between a young (20-40 years) versus an old (60-80 years) group. Based on the COVID-19 studies just discussed, the young ${ }^{7-9}$ and the living alone $e^{7,8}$ were expected to report greater psychological distress and sleep disturbances.

\section{Methods}

\section{Participants}

A $\mathrm{G}^{*}$ power analysis indicated that a sample size of 224 was required for an alpha of .05 and $80 \%$ power. The participants included individuals $(\mathrm{N}=260)$ who ranged in age from 18-82 (M=47 years). Gender was distributed 79\% female, $18 \%$ male and $3 \%$ other (non-specified). Ethnicity was distributed 68\% Non-Hispanic White, 21\% Hispanic, $3 \%$ Black and $8 \%$ other (non-specified). Professions were distributed $35 \%$ office worker, $30 \%$ academic, $15 \%$ managerial, $12 \%$ medical and $8 \%$ labor. The average income was $\$ 72,572,28 \%$ were unemployed and $69 \%$ worked at home. Twenty-three per cent lived alone.

\section{Procedure}

A flyer was posted on Facebook giving a brief description of the study including some sample items and the age criterion being greater than 18 years. The Facebook flyer included a link to the survey on Survey Monkey which included 11 scales for a total of 87 items. The survey was four weeks duration (April 1-30, 2020), and the data were directly transported to SPSS for data analyses.

\section{Measures}

The survey included several demographic items including those already mentioned (age, gender, ethnicity, profession, income, type of employment, working at home, and living alone). The following five scales were created specifically for this survey to relate to activities and stress associated with the COVID-19 lockdown. The participants rated the items on the scales from zero meaning "not at all" to three meaning "a lot" including the:

Health Scale (15 items) (Cronbach's alpha=.66) which included exercise (inside exercise, outside exercise and outside exercise with others as well as the types of exercise), touching (touching partner, kids and self as well as the types of touching), COVID-19-related safety practices including washing hands and social distancing, self-care, spiritual activities (meditating and feeling spiritual), and liking being at home. A factor analysis yielded three factors contributing to $47 \%$ of the variance on the Health Scale score: Factor 1 Self/Spiritual Care that included Meditating (.74), Self-Care (.68), and Feeling Spiritual (.77) items that together explained $23 \%$ of the variance; Factor 2 Touching that included the items Touching your kids (.75) and Touching your partner or friend (.72) that explained $14 \%$ of the variance; and Factor 3 Exercise that included the items Outside exercise (-.89) and Exercise outside with someone else (-.76) that explained $10 \%$ of the variance;

Media/Communication Scale (10 items) (Cronbach's alpha=.58) including talking on the phone, texting, on Internet, gaming, on Facebook/Instagram, spending time receiving and sending messages/media about the virus, engaging in Zoom/Skype/Facetime activities (e.g. Yoga, meditation), watching the news, watching other TV programs, and watching movies. A factor analysis yielded four factors contributing to $61 \%$ of the variance on the Media/Communication Scale score: Factor 1 Entertainment that included the items Watching movies (.84) and TV programs (.80) that explained $23 \%$ of the variance; Factor 2 Communication that included phone use (.80), texting (.70) and Zoom (.63) that explained $14 \%$ of the variance; Factor 3 Social Media that included being on internet (.78) and Facebook time (.60) that explained 13\% of the variance; and Factor 4-COVID News that included watching the news (.79) and messaging about the virus (.60) that explained $11 \%$ of the variance;

Connecting Scale (4 items) (Cronbach's alpha=.41) which included connecting with friends, trying to connect with old friends, helping children do homework, and receiving support from others;

Working Scale (6 items) (Cronbach's alpha=.61) including cooking, caregiving, housekeeping, paperwork, creative work, and working on projects/hobbies; and

Stress Scale (11 items) (Cronbach's alpha=.78) which included worrying about getting a virus, worrying about your financial status, wanting this experience to end, feeling isolated, feeling lonely, feeling bored, feeling touch deprived, snacking, drinking alcohol, napping, and 
getting "cabin fever". A factor analysis yielded three factors contributing to $56 \%$ of the variance on the Stress Scale score: Factor 1 Stimulation deprivation that included the items Feeling Isolated (.86), Feeling lonely (.86), Feeling bored (.74), Getting cabin fever (.70), and Feeling touch deprived (.65) that together explained $34 \%$ of the variance; Factor 2 Worrying that included the items Worried about finances (.67) and Worried about the virus (.47) that explained $12 \%$ of the variance; and Factor 3 Stress behaviors that included the items Napping (.68) and Snacking (.53) that explained $10 \%$ of the variance.

The standardized scales on the survey included 4 PROMIS Subscales ${ }^{10}$ (each item was rated on a 5 -point scale as $1=$ never, $2=$ rarely, $3=$ sometimes, $4=$ often, and 5=always) which included the: 1) PROMIS Anxiety Subscale ( 4 items) (Cronbach's alpha $=.88$ ) which included I felt fearful, I found it hard to focus on anything other than my anxiety, my worries overwhelmed me, and I felt uneasy;

2) PROMIS Depression Subscale (4 items) (Cronbach's alpha $=.91$ ) including I felt worthless, helpless, depressed, and hopeless;

3) PROMIS Fatigue Subscale (3 items) (Cronbach's alpha=.92) including I felt fatigued, I had trouble starting things because I'm tired, and I felt run-down; and

4) PROMIS Sleep Disturbance Subscale (4 items) (Cronbach's alpha $=.86$ ) which included my sleep quality was bad, my sleep is not refreshing, I had a problem with my sleep, and I had difficulty falling asleep.

The second standardized scale was a PTSD Screener entitled "PTSD-8: A short PTSD Inventory" (8 items) (Cronbach's alpha $=.92)^{11}$. This inventory is introduced by the statement "If you're being reminded of a traumatic experience, please rate how much the following have bothered you during the lockdown" as: 0) not at all, 1) rarely, 2) sometimes, and 3) most of the time. The items are: recurrent thoughts and memories of the event, feeling as though the event is happening again, recurrent nightmares about the event, sudden emotional or physical reactions when reminded of the event, avoiding activities that remind you of the event, avoiding thoughts or feelings associated with the event, feeling jumpy/easily startled, and feeling on guard.

The last item on the COVID-19 Lockdown Activities survey was an open-ended question "Please tell us about anything you feel that has been positive about the lockdown." Survey Monkey then provided a listing of the most frequently used words and their percentiles for that item.

\section{Data Analyses}

The data were analyzed via MANOVAs and ANOVAs on: 1) a median split by age. The median age for the median split data analysis was 50 years; and 2) comparisons between a young (20-40 years) versus an old (60-80 years) group. The resulting distribution was $15 \%$ alone in the young group and $38 \%$ alone in the old group.

\section{Results}

The significant ANOVA effects appear in tables from both the young/old group comparisons (table 1) and the median split (table 2) and for items of the scales (table 3).

Table 1. Means for significant ANOVAs for age and living condition based on group comparisons young (20-40) versus old (60-80). (Standard deviations in parentheses)

\begin{tabular}{|c|c|c|c|c|}
\hline \multirow[b]{2}{*}{ Scales Alone } & \multicolumn{2}{|c|}{ Young (20-40) } & \multicolumn{2}{|c|}{ Old $(60-80)$} \\
\hline & Yes & No & Yes & No \\
\hline Health & $26.47(4.67)$ & $32.22(5.22)$ & $29.21(5.09)$ & $33.04(4.68)$ \\
\hline Working & $12.06(2.16)$ & $16.10(3.76)$ & $14.18(2.51)$ & $15.72(3.71)$ \\
\hline Stress & $31.94(7.40)$ & $26.72(5.92)$ & $26.54(7.06)$ & $24.50(5.98)$ \\
\hline Anxiety & $11.88(3.90)$ & $10.21(3.76)$ & $9.18(3.58)$ & $8.65(3.09)$ \\
\hline Depression & $12.47(4.32)$ & $8.73(4.21)$ & $8.22(3.70)$ & $6.57(2.89)$ \\
\hline Fatigue & $10.29(3.02)$ & $8.46(2.96)$ & $7.64(3.02)$ & $6.72(2.96)$ \\
\hline Sleep & $16.00(5.60)$ & $14.83(4.58)$ & $12.39(3.78)$ & $11.37(3.89$ \\
\hline \multicolumn{5}{|c|}{ Effects } \\
\hline Health- Young & $F=3.98$ & $p=.05$ & $\mathrm{ETA}^{2}=.02$ & \\
\hline Alone & $F=28.73$ & $p=.000$ & $\mathrm{ETA}^{2}=.13$ & \\
\hline Working-Alone & $F=20.55$ & $p=.000$ & $\mathrm{ETA}^{2}=.1$ & \\
\hline Stress- Young & $F=11.80$ & $p=.001$ & $\mathrm{ETA}^{2}=.06$ & \\
\hline Alone & $F=10.69$ & $p=.001$ & $\mathrm{ETA}^{2}=.05$ & \\
\hline Anxiety- Young & $\mathrm{F}=11.10$ & $p=.001$ & $\mathrm{ETA}^{2}=.06$ & \\
\hline Depression- Young & $F=21.72$ & $p=.000$ & $\mathrm{ETA}^{2}=.11$ & \\
\hline Alone & $F=15.39$ & $p=.000$ & $\mathrm{ETA}^{2}=.08$ & \\
\hline Fatigue- Young & $\mathrm{F}=17.26$ & $p=.000$ & $\mathrm{ETA}^{2}=.09$ & \\
\hline Alone & $\mathrm{F}=6.81$ & $p=.01$ & $\mathrm{ETA}^{2}=.04$ & \\
\hline Sleep- Young & $F=20.32$ & $p=.000$ & $\mathrm{ETA}^{2}=.10$ & \\
\hline PTSD- Young & $\mathrm{F}=6.82$ & $\mathrm{p}=.01$ & $\mathrm{ETA}^{2}=.05$ & \\
\hline
\end{tabular}


Table 2. Means for significant ANOVAs for age and living condition based on median split on age. (standard deviations in parentheses)

\begin{tabular}{|l|c|c|c|c|}
\hline \multicolumn{1}{|c|}{ Scales Alone } & \multicolumn{2}{c|}{ Young } & \multicolumn{2}{c|}{ Old } \\
\hline Health & Yes & No & Yes & $32.79(5.42)$ \\
\hline Working & $26.90(4.84)$ & $32.61(5.07)$ & $29.86(5.57)$ & $15.90(3.63)$ \\
\hline Stress & $12.76(3.03)$ & $16.13(3.45)$ & $14.26(2.79)$ & $26.18(6.53)$ \\
\hline Anxiety & $30.38(6.81)$ & $26.94(5.71)$ & $27.56(6.86)$ & $9.12(3.56)$ \\
\hline Depression & $11.48(3.84)$ & $10.15(3.58)$ & $8.91(3.09)$ & $7.62(4.03)$ \\
\hline Fatigue & $11.76(4.19)$ & $8.08(3.63)$ & $7.88(3.12)$ & $7.49(3.41)$ \\
\hline Sleep & $9.60(3.06)$ & $8.15(2.97)$ & $7.62(3.02)$ & $12.93(4.56)$ \\
\hline PTSD & $15.76(4.71)$ & $14.17(4.44)$ & $12.45(4.16)$ & $13.32(5.37)$ \\
\hline Effect & $17.77(5.44)$ & $14.31(6.04)$ & $13.83(5.52)$ & \\
\hline Health - Alone Effect & & & & \\
\hline Working - Alone Effect & $\mathrm{F}=22.87$, & $\mathrm{p}=.000$ & $\mathrm{ETA}^{2}=.10$ & \\
\hline Stress - Alone Effect & $\mathrm{F}=23.71$, & $\mathrm{p}=.000$ & $\mathrm{ETA}^{2}=.09$ & \\
\hline Anxiety - Young Effect & $\mathrm{F}=6.29$, & $\mathrm{p}=.01$ & $\mathrm{ETA}^{2}=.03$ & \\
\hline Depression - Young Effect & $\mathrm{F}=11.08$, & $\mathrm{p}=.001$ & $\mathrm{ETA}^{2}=.04$ & \\
\hline Alone Effect & $\mathrm{F}=14.51$, & $\mathrm{p}=.000$ & $\mathrm{ETA}^{2}=.06$ & \\
\hline Young By Alone & $\mathrm{F}=11.94$, & $\mathrm{p}=001$ & $\mathrm{ETA}^{2}=.05$ & \\
\hline Fatigue Young Effect & $\mathrm{F}=8.98$, & $\mathrm{p}=.003$ & $\mathrm{ETA}^{2}=.05$ & \\
\hline Sleep Young Effect & $\mathrm{F}=7.83$, & $\mathrm{p}=.006$ & $\mathrm{ETA}^{2}=.03$ & \\
\hline PTSD Young Effect & $\mathrm{F}=11.11$, & $\mathrm{p}=.001$ & $\mathrm{ETA}^{2}=.03$ \\
\hline Alone Effect & $\mathrm{F}=6.02$, & $\mathrm{p}=.02$ & ETA $^{2}=.03$ \\
\hline
\end{tabular}

Table 3. Significant effects for age and living condition based on median split and group comparison young (20-40) vs. old (60-80). (<=less, $>=$ more)

\begin{tabular}{|c|c|c|c|c|c|c|}
\hline \multirow[b]{2}{*}{ Variable } & \multicolumn{2}{|c|}{ Young } & \multicolumn{2}{|c|}{ Alone } & \multicolumn{2}{|c|}{ Young/Alone } \\
\hline & Median & Y vs. $O$ & Median & Y vs. 0 & Median & Y vs. 0 \\
\hline Health Scale & & $<$ & $<$ & $<$ & & \\
\hline Outside exercise & $<$ & & $<$ & $<$ & & \\
\hline Touching kids & & $>$ & $>$ & $<$ & $<$ & $<$ \\
\hline Touching partner/ friend & & & $<$ & $<$ & & \\
\hline Washing hands & $<$ & $<$ & $<$ & $<$ & & $<$ \\
\hline Meditating & & $<$ & & & $<$ & $<$ \\
\hline Liking being home & $<$ & $<$ & & & $<$ & $<$ \\
\hline Self-care & $<$ & $<$ & & & & \\
\hline Feeling spiritual & & $<$ & & & & \\
\hline Media/ Communication Scale & & & & & $>$ & \\
\hline Texting & & & $<$ & $<$ & & \\
\hline On internet & $>$ & $>$ & & $>$ & & \\
\hline Facebook & $>$ & $>$ & & & & \\
\hline Watching news & $<$ & $<$ & & & & \\
\hline Helping with homework & & & $<$ & $<$ & & \\
\hline Working Scale & & & $<$ & $<$ & & $<$ \\
\hline Cooking & & & $<$ & $<$ & & \\
\hline Caregiving & & & $<$ & $<$ & & \\
\hline Housekeeping & & & $<$ & $<$ & & \\
\hline Paperwork & & & $<$ & $<$ & $<$ & $<$ \\
\hline Creative work & & & & $<$ & & \\
\hline Stress Scale & & $>$ & $>$ & $>$ & & \\
\hline Wanting it to end & & & & $>$ & & \\
\hline Isolated & $>$ & $>$ & $>$ & $>$ & & $>$ \\
\hline Lonely & $>$ & $>$ & $>$ & $>$ & & \\
\hline Bored & & $>$ & & & & $>$ \\
\hline Touch deprived & & & $>$ & $>$ & & \\
\hline
\end{tabular}




\begin{tabular}{|c|c|c|c|c|c|c|}
\hline Snacking & $>$ & & & & & \\
\hline Napping & $>$ & & & & & \\
\hline Cabin fever & & & & $>$ & & \\
\hline Anxiety Subscale & $>$ & $>$ & & $>$ & & \\
\hline Fearful & $>$ & & & & & \\
\hline Focus on anxiety & $>$ & $>$ & & $>$ & & \\
\hline Overwhelming worries & $>$ & $>$ & & & & \\
\hline Uneasy & & & & & & $>$ \\
\hline Depression Subscale & $>$ & $>$ & $>$ & $>$ & $>$ & \\
\hline Worthless & $>$ & $>$ & $>$ & $>$ & $>$ & \\
\hline \multicolumn{7}{|l|}{ Helpless } \\
\hline Depressed & $>$ & $>$ & $>$ & $>$ & $>$ & \\
\hline \multicolumn{7}{|l|}{ Hopeless } \\
\hline Fatigue Subscale & $>$ & $>$ & $>$ & & $>$ & $>$ \\
\hline Fatigued & $>$ & $>$ & $>$ & $>$ & $>$ & \\
\hline Trouble starting & $>$ & $>$ & $>$ & $>$ & $>$ & \\
\hline Run-down & & $>$ & & & & \\
\hline Sleep Disturbance & $>$ & $>$ & $>$ & & & \\
\hline Bad quality & $>$ & $>$ & & & & \\
\hline Not refreshing & $>$ & $>$ & & & & \\
\hline Problem & $>$ & $>$ & & & & \\
\hline Falling asleep & $>$ & $>$ & & & & \\
\hline Trauma experience & $>$ & $>$ & $>$ & $>$ & & \\
\hline PTSD Inventory & $>$ & $>$ & $>$ & & & \\
\hline Memories & $>$ & $>$ & $>$ & $>$ & & \\
\hline Nightmares & & $>$ & & & & \\
\hline Avoiding activities & $>$ & $>$ & & & & \\
\hline Avoiding thoughts & $>$ & $>$ & & & & \\
\hline Jumpy & $>$ & & & & $>$ & \\
\hline On guard & $>$ & & $>$ & $>$ & & \\
\hline
\end{tabular}

The young effects are first presented, then the alone effects and finally the young/alone interaction effects. MANOVAs were significant for the young/old group comparisons (Wilks' Lambda $F=3.82, p=.000$, eta ${ }^{2}=.22$ and for the median split (Wilks' Lambda $F=3.23, \mathrm{p}=.001$, eta ${ }^{2}=.16$ ).

\section{Young Effects}

As can be seen in tables 1 and 2, several significant young/old effects were noted on the scales and significant effects for the items of the scales are given in table 3 . They are: 1) the Health Scale score which was significant only on the group comparisons analysis (table 1). Table 3 lists the significant Health scale items as the young engaging in less outside exercise, more touching kids, less washing hands, less meditating, less liking being home, less selfcare, and less feeling spiritual; 2) a few items on the Media Scale which are significant, although the total scores on the scale were not, and they included the young spending more time on the Internet, more time on Facebook, and less time watching the news; 3) the Stress Scale score which was only significant for the group comparisons. The Stress Scale items that were significant included the young feeling more isolated, lonely, bored, and engaging in more snacking and napping: 4) the Anxiety Subscale score was significant for both the group comparison and the median split analyses (as can be seen in tables 1 and 2). The items that showed significant young versus old effects were the young being more fearful, focused on anxiety, having overwhelming worries, and feeling uneasy; 5) the Depression Subscale was significant for both the group comparisons and the median split. The depression scale items that showed greater effects for the young included feeling worthless, helpless, depressed, and hopeless; 6) the Fatigue Subscale score was significant for both the comparisons and the median split. The items on the fatigue scale suggested greater fatigue, difficulty getting started, and feeling run down by the young; 7) the Sleep Disturbance Subscale score was significant for both the group comparison and the median split. The significant sleep disturbance items included the young having bad sleep quality, not having refreshing sleep, having sleep problems, and having difficulty falling asleep; and 8) the PTSD-8 scores were significant for both the group comparison and the median split analyses. The significant PTSD-8 items included the introductory item on trauma experience with the young expressing more trauma experience), and then the items including having more memories of the experience, avoiding activities that reminded them of experience, 
avoiding thoughts about the experience, being more jumpy, and be more on guard.

\section{Alone Effects}

The significant alone ANOVAs on the scales are given in table 1 for the group comparisons and table 2 for the median split analyses. Significant items on those scales are given in table 3 . The effects were noted for the following scales and items: 1) Health Scale scores were significant for both the group comparisons and the median split data analyses. The significant health scale items suggested that the living alone versus the living with someone else reported less outside exercise, less touching kids, less touching partner/friend, and less washing hands; 2) although the Media Scale scores were not significant, the scale items showed that folks alone were spending less time texting and more time on the Internet; 3 ) Working Scale scores were significant for both group comparisons and median split data analyses. The items on that scale suggested that folks living alone spent less time cooking, caregiving, housekeeping, doing paperwork, and engaging in creative work; 4) the Stress Scale scores were significant for both the group comparison and median split analyses. The items on the stress scale showed that the alone group was expressing more wanting the lockdown to end, feeling isolated, lonely, and touch deprived as well as having more cabin fever; 5) although Anxiety Subscale scores were not significant for either the group comparisons or the median split data analyses, the alone people showed more focus on anxiety; 6) the Depression Subscale scores were significant for both the group comparison and the median split data analyses. All of the depression scale items were significant for the alone group including feeling more worthless, helpless, depressed, and hopeless; 7) the Fatigue Subscale score was only significant for the group comparison analysis. The items that were significant for the alone group were feeling fatigued, and having trouble getting started; 8) the PTSD-8 was only significant for the median split data analysis. The only individual item that was greater for the alone group was the on guard item.

\section{Young by Alone Interaction Effects}

The only significant young by alone interaction effect was on the Depression Subscale. Significant young by alone interaction effects were noted for all the depression items including feeling more worthless, helpless, depressed, and hopeless There were also a number of significant young by alone interaction effects for other scale items including less touching kids, less washing hands, feeling more isolated, bored, fatigued, and jumpy.

\section{Discussion}

Some of these effects would be expected. For example, the greater use of social media (i.e. internet and Facebook) by the young group is not surprising. Both internet addiction and Facebook addiction have been noted for youth as early as adolescence ${ }^{12,13}$. And, that those living alone were doing less work at home (i.e. cooking and caregiving) was also not surprising. Further, that those living alone gave higher ratings for touch deprivation would be expected. Touch deprivation has been significantly related to not just living alone but also to being isolated and lonely during the COVID-19 lockdown ${ }^{14}$.

Feeling isolated and lonely were significant effects for all three groups in these data analyses including the young, the alone and the young alone. The word loneliness, although derived from the word alone, is thought to be equivalent to social isolation in studies on loneliness in non-COVID samples ${ }^{15}$. And, across the lifespan, loneliness has been reportedly more common in young adults (20$70 \%)$ than older adults $(11-30 \%)^{16}$. Loneliness, in turn, has predicted less physical activity ${ }^{17}$. Those living alone in the current COVID-19 sample were not only less actively working at home, but were also getting less exercise. Less exercise, in turn, has been associated with depression and fatigue $^{14}$. Although $27 \%$ of this sample reported engaging in exercise "a lot", as many as $17 \%$ responded "not at all" to the question on outside exercise. And, exercise has been noted to reduce depression in COVID-19 samples ${ }^{14,18}$. Loneliness (social isolation) is thought to increase activation of the hypothalamic pituitary axis ${ }^{15}$. Cortisol, the stress hormone that is then increased, compromises immune function by reducing natural killer (NK) cell number and natural killer cell activity, which in turn kill viral cells, for example, HIV cells ${ }^{19}$. Although, NK cells and NK activity have enhanced immune function in HIV, their effects on immune function in COVID-19 are unknown. Exercise would be expected to enhance immune function, via the stimulation of pressure receptors under the skin, in turn increasing vagal activity, decreasing cortisol and increasing NK activity ${ }^{20}$.

Depression and fatigue were also significant effects for all three groups. The young, alone and the young alone had higher ratings on the PROMIS depression and fatigue subscales. Depression explained a significant amount of the variance (52\%) in COVID-19 stress in an earlier report on this sample, and both the young and the alone had higher stress scores in the current data analyses ${ }^{8}$. In the earlier report on stress and sleep, fatigue explained $52 \%$ of the variance in sleep disturbances ${ }^{8}$. When regressions have been conducted on fatigue and sleep disturbances in a community sample, anxiety, depression, and PTSD contributed to significant variance in both sleep and fatigue, and sleep and fatigue were significantly related ${ }^{21}$. However, direction of effects cannot be determined, as sleep and fatigue could be reciprocally related or at least they could have exacerbated pre-existing conditions in this cross-sectional study. 
Fatigue is an ambiguous term, as it could be defined as exhaustion from hard work (which was not happening in this alone sample), but it has also been anecdotally referred to as "quarantine fatigue" during this COVID-19 pandemic. Quarantine fatigue would be expected to worsen over a period of time. And, the Survey Monkey output from this study suggested that the prevalence (percentiles) for all of these problems were higher at the end of the lockdown than those in the middle of the survey data collection, suggesting that "quarantine fatigue" may be contributing to the worsening of these problems.

Despite the already mentioned significant variance that fatigue contributed to sleep in the larger COVID-19 data base, sleep disturbances were only greater for the young in the current data analyses. The young also had uniquely higher PTSD scores. These effects are consistent with the association between sleep disturbances and posttraumatic stress symptoms in a COVID-19 sample in China, although, once again, that was a cross-sectional sample in which directionality of effects could not be determined ${ }^{1}$. The significant association between anxiety and sleep disturbance has also been reported for a younger COVID-19 sample ( $<35$ years) in China, a syndrome that the authors referred to as the "hypochondriac concern about getting the virus". Although anxiety and particularly "worries" were expressed by the young in this survey, "worry about getting the virus" was a universal concern reported by both the young and old and the living alone and living with others in the current study.

The limitations of this survey are that it is a crosssectional sample in which causality inferences cannot be made. With the sudden onset of pandemics, pre-existing data are not typically available. This was also a nonrepresentative sample (both on gender and ethnicity) so that the data are not generalizable. Unfortunately, the geographic distribution of the participants may also be unrepresentative, although that is unknown. The data are also based on self-report with its frequently noted problems, although the anonymity of the survey would suggest significant veridicality of the data. Despite these limitations, the significantly greater problems for the young, the alone and the young alone in this sample suggest a high-risk profile that might be used to identify those who are in particular need of prevention/intervention protocols during pandemic lockdowns like COVID-19.

\section{Conclusion}

These data suggest that the young, the living alone, and the young living alone are experiencing significantly more loneliness, depression, and fatigue than others during a COVID-19 lockdown. The data also suggest that potential buffers for these problems are meditation, touching their partners and kids, and indoor exercise, outdoor exercise, and outdoor exercise with others. These data may help inform current and future intervention efforts to reduce these problems during COVID-19 and other lockdowns.

\section{References}

1. Liu, N, Zhang F, Wei C, et al. Prevalence and predictors of PTSS during COVID-19 outbreak in China hardest-hit areas: Gender differences matter, Psychiatry Research. 2020.

2. Mak IW, Chu CM, Pan PC, et al. Risk factors for chronic posttraumatic stress disorder (PTSD) in SARS survivors. Gen. Hosp. Psychiatry. 2010; 32 (6): 590-598. https://doi.org/10.1016/j. genhosppsych.2010.07.007.Retrievedfromhttps://www.ncbi.nlm. nih.gov/pubmed/21112450

3. Forte G, Faviori F, Tambelii R, et al. COVID-19 pandemic in the Italian population: Validation of a post-traumatic stress disorder questionnaire and prevalence of PTSD symptomatology. International Journal of Environmental Research and Public Health. 2020; 17: 4151.

4. 4. Mazza C, Ricci E, Biondi S, et al. A nationwide survey of psychological distress among Italian people during the COVID-19 pandemic: Immediate psychological responses and associated factors. International Journal of Environmental Research and Public Health. 2020; 17: 31-65. doi:10.3390/ijerph17093165

5. Altena E, Baglioni C, Espie CA, et al. Dealing with sleep problems during home confinement due to the COVID-19 outbreak: Practical recommendations from a task force of the European CBT-I Academy. Journal of Sleep Research. doi-org.fgul.idm.oclc. org/10.1111/jsr.13052

6. Cellini N, Canale N, Mioni G, et al. Changes in sleep pattern, sense of time and digital media use during COVID-19 lockdown in Italy. Journal of Sleep Research. 2020. doi. org/10.1111/jsr.13074

7. Stanton R, To Q, Khalesi S, et al. Depression, Anxiety and Stress during COVID-19: Associations with Changes in Physical Activity, Sleep, Tobacco and Alcohol Use in Australian Adults International Journal of Environmental Research and Public Health. 2020; 17(4065): 4065 DOI 10.3390/ijerph17114065

8. Field T, Mines S, Poling S, et al. Stress and sleep disturbances during COVID-19 lockdown. Journal of Psychology and Mental Health Care. 4(5): 1-5.

9. Huang Y, Zhao N. Generalized anxiety disorder, depressive symptoms and sleep quality during COVID-19 outbreak in China: A web-based cross-sectional survey Psychiatry Research. 2020; 288: 112954.

10. Dewitt B, Feeny D, Fischhoff B, et al. Estimation of a preference-based summary score for the patient reported outcomes measurement information system: The PROMIS-preference (PROPr) scoring system. Medical Decision Making. 2018; 38: 683-698.

11. Hansen M, Anderson TE, Armour C, et al. PTSD-8: A short PTSD inventory. Clinical Practice \& Epidemiology in Mental Health. 2010; 6: 101- 108.

12. Field T. Internet Addiction in Adolescents: A Review. Journal of Addictions and Therapies. 2018; 1: 1-11.

13. Field T. Facebooking in adolescents: A narrative review. Journal of Addiction and Adolescent Behavior. 2020.3(4): 1-11.

14. Field T, Poling S, Mines S, et al. Touch deprivation and exercise during COVID-19 lockdown Medical Research Archives. 2020. 8(8): 1-12.

15. Cacioppo J, Cacioppo S, Capitano J, et al. The neuroendocrinology of social isolation. Annual Review of Psychology. 2015; 66: 733-767.

16. Qualter P, Vanhalst J, Harris R, et al. Loneliness across the life span. Perspectives on psychological science. 2015 doi/ full/10.1177/1745691615568999?

17. Hawkley L, Thisted R, Cacioppo J. Loneliness predicts reduced physical activity: Cross-sectional \& longitudinal analyses. Health Psychology. 2009; 28: 354-363. DOI:10.1037/a0014400 
18. Banno M, Harada Y, Taniguchi, M, et al. Exercise can improve sleep quality: a systematic review and meta-analysis. PeerJ. 2018; 6: 5172. DOI $10.7717 /$ peerj. 5172

19. Diego M, Field Tl, Hernandez-Reif M, et al. HIV adolescents show improved immune function following massage therapy. International J. Neuroscience. 2001; 106: 35-45.
20. Field T. Exercise research on children and adolescents. Complementary Therapies in Clinical Practice. 2012; 18: 54-59.

21. McCallum S, Batterham, A, Calear L, et al. Associations of fatigue and sleep disturbance with nine common mental disorders. Journal of Psychosomatic Research 2019; 123: 109727. 